\title{
PALATALLY POSITIONED TWO MESIODENS: A CASE REPORT
}

\author{
Dr. Sudhanshu Agrawal, ${ }^{1}$ Dr. Hemant Kumar Halwai ${ }^{2}$ \\ 1. Assistant Professor, Dept Of Periodontics, UCMS College Of Dental Surgery, Bhairahawa \\ 2. Associate Professor, Dept Of Orthodontics, UCMS College Of Dental Surgery, Bhairahawa
}

Correspondence : drsudhanshu_bds@hotmail.com

\section{ABSTRACT}

Mesiodens is a supernumerary tooth located in the anterior maxilla, placed palatally, labially or in between the maxillary central incisors. It may be single or paired, erupted or impacted and at times even inverted. This case report describes a palatally positioned two mesiodens in an 8-year-old male. The clinical and radiographic appearance and therapeutic considerations are presented. The purpose of this article is to alert the clinician to the importance of radiographic localization prior to surgical intervention, because in some instances a labial surgical approach is preferred over the traditional palatal technique. In this case a labial surgical approach was utilized which allowed for greater conservation of alveolar bone and improved access during removal of the mesiodens teeth.

Key Words : impacted, mesiodens, palatal

\section{INTRODUCTION:}

The term mesiodens was coined by Bolk (1917) to denote an accessory or supernumerary tooth situated in between the maxillary central incisors. ${ }^{1,2}$ It is usually a small tooth with a cone- or - peg shaped crown and a short root. The presence of a mesiodens should be suspected if there is delayed eruption of the permanent incisors or if the central incisors are displaced, malposed or exhibit spacing. The literature reports that $80 \%$ to $90 \%$ of all supernumerary teeth occur in the maxilla. ${ }^{3}$

\section{CASE REPORT:}

An 8-year-old male reported to Department of Periodontics in UCMS College Of Dental Surgery with a chief complaint of spacing in the upper front jaw since the permanent teeth have erupted. Two mesiodens were present and visible (Fig. 1). He was a normal healthy

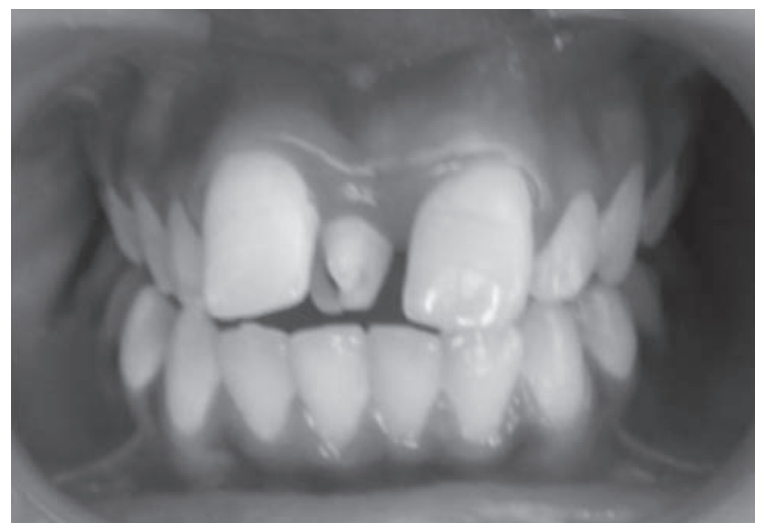

Fig.1 Clinical picture of mesiodens child with a medical and dental history which was both noncontributory. He presented in the permanent dentition stage with a $60 \%$ overbite and an end-to-end molar relationship, primary canines relating as Class I. Maxillary anterior spacing was slightly excessive with a 1-2 mm midline diastema present. Radiographs were taken in order to localize the supernumerary tooth roots and assess the potential surgical approach.

\section{Radiographic Examination and Treatment Plan:}

The periapical radiograph depicted vertical long axis of two mesiodens (Fig. 2). Root development appeared normal with the mesiodens primarily affecting the tooth position. From the radiographic survey it was determined that the mesiodens was likely to be inverted with the long axis oriented vertically. A labial surgical approach was planned to execute the mesiodens followed by orthodontic space closure after healing.

Fig.2 Radiographic picture of two mesiodens

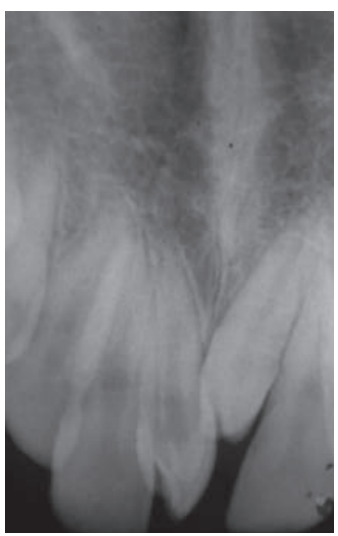




\section{Treatment}

The surgical procedure was performed in the Department of Periodontics in local anesthesia under antibiotic coverage started two days prior. After anesthesia, an elliptical incision was made from the distal aspect of the maxillary right lateral incisor to the distal aspect of the maxillary left lateral incisor. A full thickness flap then was reflected with a periosteal elevator and both the mesodens were removed surgically (Fig.3, 4). A slight elevation in the alveolus was evident midway between the root apices of the permanent central incisors.

Care was taken to avoid excessive bone removal or damage to roots of the adjacent permanent teeth. Silk suture were placed and post-operative instruction were explained and medication prescribed. The sutures were removed 1 week postoperatively with normal healing at the surgical site. Six month follow-up found continued eruption of the maxillary permanent lateral incisors with minimal scar formation in the area. Patient was not ready for fix mechanotherapy therefore initiation of comprehensive orthodontic treatment with a removable appliance was done in the Department of Orthodontics with the progressive activation of the appliance was done at three weeks of interval (Fig.5,6).

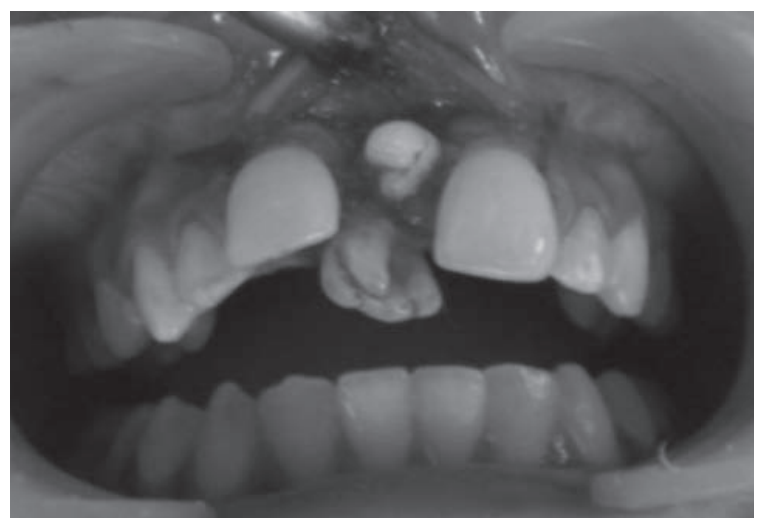

Fig. 3 Surgical procedure

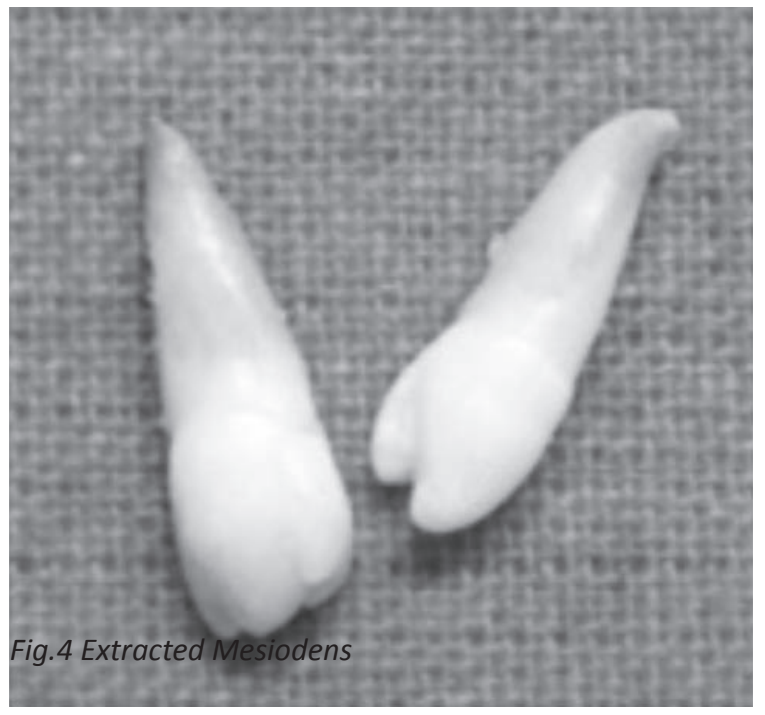

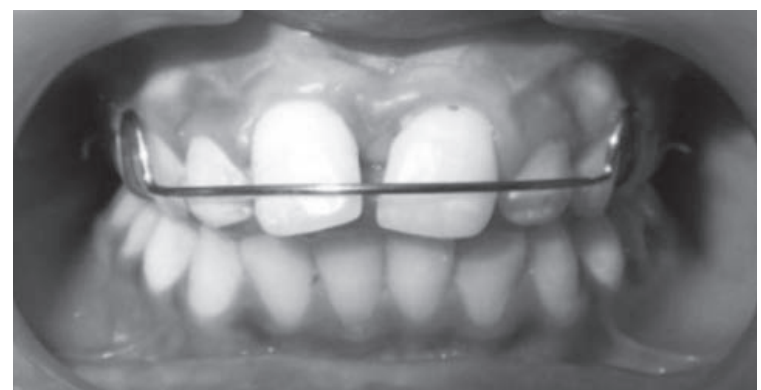

Fig.5 Orthodontic treatment to close diastema

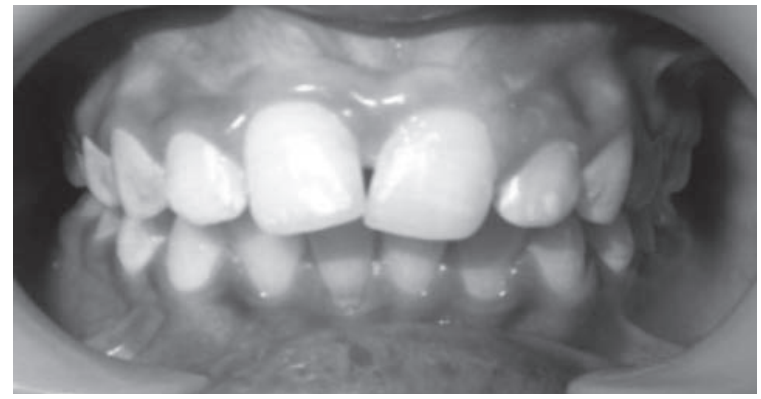

Fig.6 Post treatment picture

\section{DISCUSSION:}

A mesiodens is a supernumerary tooth located in the maxillary central incisor region. The overall prevalence of mesiodens is between $0.15 \%$ to $1.9 \%$. Its incidence is estimated to be between $46 \& 67 \%$ of all supernumerary teeth. Supernumerary teeth may occur in isolation or as part of a syndrome such as cleidocranial dysplasia, Gardner's syndrome, cleft lip \& palate etc. ${ }^{4}$

Mesiodens can occur individually or as multiples and often do not erupt. According to Asaumi $\mathrm{Jl}$ et $a l^{5}$ the number of supernumerary teeth was one in 146 cases (73\%), two in 52 cases (26\%) and three in 2 cases (1\%). $76.8 \%$ of the children reported by Gunduz K et al had one mesiodens \& $23.1 \%$ had two mesiodens bilaterally to the midline. In our case described, 2 mesiodens were located palatally.

Mesiodens can be classified on the basis of their occurance in the permanent dentition (rudimentary mesiodens) or primary dentition (supplementary mesiodens) and according to the morphology as conical, tuberculated or molariform. Supplementary mesiodens resemble natural teeth in both size and shape where as rudimentary mesiodens exhibit abnormal shape with smaller size. ${ }^{3,6}$ Conical mesiodens usually occur singly. They are generally peg shaped and are usually located palatally between the maxillary central incisors, tending to displace the erupting permanent central incisors. They often have a completely formed root and can erupt into the oral cavity. However they may be inverted with the crown pointing superiorly in which case they are likely to erupt into the nasal cavity. Only occasionally do the mesiodens imitate the shape of maxillary lateral incisors (eumorphic). ${ }^{7}$ 


\section{ORTHODONTIC JOURNAL OF NEPAL}

Clearly, there are indications both for the early surgical removal of supernumeraries as well as for their supervised observation. The case presented depicts two mesiodens that did not change position in a reasonable period of time. They were positioned such that a diastema was created between the central incisors. Their effect also altered the eruption path of the permanent lateral incisors. In the present case one would not expect significant improvement in the mesiodens position therefore its surgical removal was initiated.

\section{CONCLUSION}

Surgery involving a palatal flap is the most typical for impacted maxillary midline supernumerary teeth. In this case, a labial surgical approach was utilized which allowed increased visualization of the mesiodens and greater ease of removal. The background and rationale for this approach is presented and should be considered in selected cases, particularly for older children with inverted mesiodens.

\section{REFERENCES:}

1. Gorlin R. J., Goldman H. M. Thoma's Oral Pathology, Vol 16th Ed. The C. V. Mosby Co., 1990.

2. J Randle Luten, Jr. The prevalence of supernumerary teeth in primary \& mixed dentition. J Dent Child 1967;34:346-53.

3. Primosch R. E. 'Anterior supernumerary teeth - Assessment and surgical intervention in children'. Pediatr. Dent 1981. 3(2); 204215.

4. Sharma A. Familial occurance of mesiodens - A case report. J Indian Soc Pedod Prev Dent 2003; 21: 84-85.

5. Asaumi Jl, Shibita Y, Yangi Y, Hisatomi M, Matsuzaki H, Konouchi H, Kishi K . Radiographic examination of mesiodens and their associated complications. Dentomaxillofac Radiol 2004; 33: 125 -127.

6. Russell KA, Magdalena A Folwarczna. Mesiodens - Diagnosis and management of a common supernumerary tooth. J. Can Dent Assoc 2003; 69(6): 362-6.

7. Atasu M, Orguneser A. Inverted impaction of a mesiodens: a case report J. Clin Pediatr Dent 1999;23(2):143-5.

8. Brunning LJ, Dunlap L, Mergele ME: Report of supernumerary teeth in Huston, Texas, school children. ASDCJ Dent Child, 1957; 24:98-105.

9. Enlow DH: The facial growth process, in Handbook of Facial Growth, 2nd ed. Philadelphia; WB Saunders Co, 1982 pp 62-74.

10. Hogstrom A, Andersson L : Complication related to surgical removal of anterior supernumerary teeth in children. ASDCJ Dent Child, 1987;54:341-43.

11. Hurlen B, Humerfelt D: Prevalence of premaxillary supernumerary teeth in Norwegianc hildren: a radiographic study. Dentomaxilolofac Radiol, 1984;13:109-15.

12. Kaler LC: Prevalence of mesiodens in a pediatric Hispanic population. ASDCJ Dent Child, 1988;55:137-38.

13. Langllais RP, Langland OE, Morris CR: Radiographic localization techniques. Dent Radiog Photog, 1979;52:69-77. 